đúng và đủ 17 tiêu chí) là 169 và tỷ lệ là $39,76 \%$, số mũi tiêm không an toàn (mũi tiêm không thực hiện $\geq 1$ tiêu chí trong 17 tiêu chí) là 256 và tỳ lệ là 60,24\%.

\section{KẾT LUẬN}

Qua kết quả khảo sát vê tiêm an toàn của 85 điêu dưỡng tại khoa Cấp cứu, Hồi sức và khối Ngoại Bệnh viện 19-8 Bộ công an, năm 2014, chúng tôi rút ra một số kết luận như sau:

- Tỷ lệ tiêm an toàn của điêu dưỡng: 39,76\%

- Các yếu tố liên quan:

+ Nhóm tuổi 41-50 có tỷ lệ TAT cao nhất: 75\%; nhóm tuổi > 50 có tỷ lệ TAT thấp nhất: chiếm $20 \%$

+ Khoa Hồi sức có tỷ lệ tiêm an toàn cao nhất: 57,5\%, khoa Ngoại Tổng hợp có tỷ lệ tiêm an toàn thấp nhất: $21,82 \%$.

\section{TÀI LIỆ THAM KHẢO}

1. Đào Thành (2010), "Kết quả nghiên cứu đánh giá thực trạng tiêm an toàn tại 13 bệnh viện lựa chọn năm 2013", Hôi Điều dương Viêt Nam.

2. Phạm Đức Mục ( 2005), "Đánh giá kiến thức về Tiểm an toàn và tân xuất rủi ro do vât sắc nhọn đối với Điêu dưỡng - Hộ sinh tại 8 Tỉnh đại diện, 6 tháng đâu năm 2005", Kỷ yếu đề tài nghiên cứu khoa hoc điều dưỡng toan quốc lần thứ II, Hội Điều dưỡng Việt Nam, Hà Nội, tr.224-232

3. Bô y tế vu khoa hoc và đào tao "Điều dưỡng cở bản", Nhà xuất bản y học, Hà Nội (2002), trang $160-190$.

4. Bộ y tế (2012), Hướng dẫn tiêm an toàn trong các cở sở khám bệnh, chữa bệnh, Hà Nội.

5. Phan Thi Dung (2009), Nghiên cứu khảo sát về tiêm an toàn tai bênh viên Viêtt Đức năm 2009, Hà Nôii

6. Tài liệu Hội nghi khoa hoc Điều dưỡng Bệnh viện Hữu nghi Viêt Đức lần thứ V, trang 23,33.

7. WHO, (2002), Department of Protection of the Human Environment và Department of Vaccines and Biologicals (2002), "First, do no harm"introducing auto-disable syringes and ensuring injection safety in immunization systems of developing countries, Geneva, Switzerland.

\title{
TỶ LÊ THIẾU Cơ VÀ MộT SỐ YẾU Tố LIÊN QUAN TRÊN BỂNH NHÂN CAO TUỔI ĐÁI THÁO ĐƯỜ'NG TÍP 2
}

\section{TÓM TẮT}

Muc tiêu: Xác đinh tỷ lê thiếu cơ và khảo sát môt số yếu tố liên quan đến thiếu cơ ở bệnh nhân cao tuổi ĐTĐ típ 2. Đối tượng và phương pháp: Thiết kế nghiên cứu là mô tả cắt ngang trên bệnh nhân $\geq 60$ tuổi có bệnh ĐTĐ típ 2 đến khám tại phòng khám ngoại trú bệnh viện Quân Y 175 trong khoảng thời gian từ tháng 11/2019 đến tháng 03/2020 thóa các tiêu chuẩn chọn mấu. Kết quả: Nghiên cứu này thu nhận 255 bệnh nhân với tuổi trung bình là 76,76 7,3 (tuổi), trong đó nam chiếm tỷ lệ $81,6 \%$. Tỷ lệ thiếu cơ chung trên các bệnh nhân có đái tháo đường là $22,7 \%$. Khi phân tích logistic đa biến, chúng tôi ghi nhận chỉ đặc điểm thời gian mắc bệnh đái tháo đường $(\mathrm{OR}=0,37, \mathrm{KTC} 95 \% 0,14-0,98, \mathrm{p}=0,045)$ và thể trang $(\mathrm{OR}=4,57, \mathrm{KTC} 95 \% 2,76-7,56, \mathrm{p}<0,001)$ là 2 yểu tố có liên quan với thiếu cơ. Kết luân: Thiếu cơ chiếm tỷ lệ khoảng gân $1 / 4$ dân số người cao tuổi bi đái tháo đường. Thời gian bi đái tháo đường và thể trạng là hai yếu tố có liên quan đến thiếu cơ.

Tư khóa: Thiếu cơ, người cao tuổi, đái tháo đường típ 2.

\footnotetext{
${ }^{1}$ Bệnh viện175, TP Hồ Chí Minh

${ }^{2}$ Đai học Y Dượ TP Hồ Chí Minh

${ }^{3}$ Bềnh viên Thống Nhất, TP Hồ Chí Minh

Chịu trách nhiệm chính: Nguyễn Văn Tân

Email: nguyenvtan10@ump.edu.vn

Ngày nhận bài: 3/12/2020

Ngày phản biên khoa hoc: 4/1/2021

Ngày duyệt bài: 29/1/2021
}

\section{SUMMARY \\ PREVALENCE AND SOME FACTORS RELATED TO SARCOPENIA IN ELDERLY PATIENTS WITH TYPE 2 DIABETES MELLITUS}

Objective: To determine the prevalence and investigate some factors related to sarcopenia in elderly patients with type 2 diabetes mellitus. Subjects and methods: research design was crosssectional description in patients $\geq 60$ years old with type 2 diabetes mellitus who visited the outpatient clinic at 175 Military Hospital from November 2019 to March 2020 with all patients who met the study inclusion criteria. Results: This study enrolled 255 patients with an average age of $76.76 \pm 7.3$ (age), of which the rate was $81.6 \%$ for men. The prevalence of sarcopenia in elderly patients with type 2 diabetes mellitus was $22.7 \%$. When analyzing multivariate logistic, we recorded only duration of diabetes mellitus (OR $=0.37,95 \%$ CI $0.14-0.98, p=0.045)$ and body mass index $(\mathrm{OR}=4.57,95 \%$ CI 2.76-7.56, $\mathrm{p}<0.001)$ were two factors associated with sarcopenia. Conclusion: sarcopenia accounted for nearly a quarter of the elderly patients with type 2 diabetes mellitus. Diabetes duration and body mass index were two factors related to sarcopenia.

Keywords: Sarcopenia, the elderly, type 2 diabetes mellitus.

\section{I. ĐặT VẤN ĐỀ}

Thiếu cơ (sarcopenia) đang trở thành một vẫn đề sức khỏe ngày càng phổ biến ở người 
cao tuổi (NCT) và gần đây đã thu hút sự chú ý của nhiều chuyên gia. Theo đồng thuận của nhóm các chuyên gia Châu Âu (EWGSOP) về thiếu cơ thì thiếu cơ có thể được chẩn đoán dựa trên giảm khối lượng cơ kèm theo giảm chất lượng cơ (bao gồm sức cơ và hoạt động chức năng của cơ) [1]. Đái tháo đường (ĐTĐ) là bệnh khá phổ biến và gia tăng nhanh chóng trên toàn thế giới. Một số nghiên cứu cho thây bệnh nhân ĐTÐ típ 2 có tỷ lệ thiếu cơ cao hơn người bình thường 1,56 lần, đặc biệt đối với người trên 70 tuổi thì nguy cơ tăng gẩp 2,0-2,3 lần. Thiếu cơ trên bệnh nhân ĐTĐ típ 2 cao tuổi làm tăng nguy cơ bị té ngã, rối loạn vận động, nguy cơ gãy xương, rối loạn chuyển hóa, giảm chất lượng cuộc sống, tăng tỷ lệ nhập viện và tử vong [2]. Hiện tại, trong nước chưa có nghiên cứu về thiếu cơ trên bệnh nhân cao tuổi đái tháo đường típ 2. Do đó, nhận thấy tầm quan trọng và cần thiết của vấn đề này nên chúng tôi thực hiện nghiên cứu này tại bệnh viện quân Y 175 nhằm xác định tỷ lệ thiếu cơ và khảo sát một số yễu tố liên quan đến thiếu cơ ở bệnh nhân cao tuổi ĐTĐ típ 2.

\section{II. ĐỐI TƯỢNG VÀ PHƯƠNG PHÁP NGHIÊN CỨU}

2.1. Đối tượng: Tất cả bệnh nhân $\geq 60$ tuổi có bệnh lý ĐTÐ típ 2 đến khám tại phòng khám ngoại trú bệnh viện Quân Y 175 trong khoảng thời gian từ tháng 11/2019 đến tháng 03/2020 thỏa các tiêu chuẩn chọn mẫu bao gồm bệnh nhân $\geq 60$ tuổi, được chẩn đoán ĐTĐ típ 2 dựa theo tiêu chuẩn của Hiệp Hội đái tháo đường Hoa Kỳ (ADA) 2019, đồng ý tham gia nghiên cứu; chúng tôi loại ra khỏi nghiên cứu các trường hợp sau: bệnh nhân đang trong giai đoạn cấp tính của bệnh lý cơ xương khớp, đang mắc các bệnh như di chứng tai biến mạch máu não (yếu, liệt vận động chi), bệnh nhược cơ, khuyết tật chi, suy tim nặng, bệnh tâm thần, xơ gan, bệnh phổi mạn, bệnh thận mạn giai đoạn cuối, ung thư giai đoạn tiến xa.

\subsection{Phương pháp nghiên cứu}

Thiết kế nghiên cứu: Mô tả cắt ngang, chọn mẫu thuânn tiện, không xác suất.

Cỡ mẫu được tính theo công thức:

$$
n=Z_{1-\alpha / 2}^{2} \frac{p \times(1-p)}{d^{2}}
$$

Trong đó: $n$ : cõ̃ mẫu tối thiểu; $Z(1-\alpha / 2)=$ 1,96 với nguy cơ sai lầm $a=0,05$ và khoảng tin cậy 95\%; p: tỷ lệ thiếu cơ ở bệnh nhân ĐTĐ típ 2 ở một nghiên cứu tiến hành tại Trung Quốc là $14,8 \%$ [3], chọn $p=0,148$; d: sai số cho phép, chọn $\mathrm{d}=0,05$; như vậy, cỡ mấu ít nhất là 194 bệnh nhân.
Các bước tiến hành nghiên cứu: Nghiên cứu viên giải thích rõ mục tiêu nghiên cứu và đối tượng phải đồng ý tham gia nghiên cứu (bằng văn bản) mới tiến hành thu thập số liệu. Các thông tin hành chính, bênh sử, tiền sử bản thân và gia đình, khám lâm sàng ghi nhận các triệu chứng cơ năng và thực thể theo bảng thu thập số liệu soạn sẵn. Ghi nhận trị số chiều cao, cẩn năng, huyết áp, HDL - Cholesterol, LDLCholesterol, Cholesterol toàn phần, Triglyceride, đường huyết tĩnh mạch, \%HbA1c, Creatine huyết thanh.

Huyết áp được đo bằng máy đo huyết áp tự động BPBIO 170 của hãng Medisol. Chiêu cao, cần nặng: chiều cao được đo bằng sóng siêu âm Inbody Inlab, cân nặng được đo bằng cân Inbody Dial cũa hãng Medisol. Khối lượng cơ được tính theo công thức nhân trắc; lực bóp tay: dụng cụ đo là áp lực kế cầm tay điện tử Jamar $5030 \mathrm{J1}$, đơn vị đo tính bằng kilogam $(\mathrm{kg})$. Nghiên cứu viên cho bệnh nhân ngồi trên ghế, khuỷu tay gấp $90^{\circ}$ so với cẳng tay, yêu cầu bệnh nhân bóp từ từ và hết sức trong vòng 3 giây, thực hiên cả ở hai tay, kết quả là tri số trung bình lực bóp tay lớn nhất ở tay phải và trái. Tốc độ đi bình thường trong $6 \mathrm{~m}$ : cho bệnh nhân đi bộ $10 \mathrm{~m}$, với tốc độ nhanh nhất có thể trong giới hạn an toàn và tính tốc độ trong khoảng từ $2 \mathrm{~m}$ đến $8 \mathrm{~m}$. Tính thời gian theo đơn vị giây và vận tốc theo đơn vị mét/giây $(\mathrm{m} / \mathrm{s})$.

Định nghĩa các biến số trong nghiên cứu:

- Chẩn đoán xác định thiếu cơ khi có giảm khối lương cơ kèm với giảm tốc đô đi bô hoặc giảm sức cơ [3]. Phân loại các giai đoạn thiếu cơ là biến liên tục gồm 3 giá trị tiền thiếu cơ (chỉ giảm khối lượng cơ), thiếu cơ (giảm khối lượng cơ kèm với giảm tốc đô đi bô hoặc giảm sức cơ), thiếu cơ nặng (giảm khối lượng cơ kèm với giảm tốc độ đi bộ và giảm sức cơ). -Tình trạng dinh dưỡng là biến thứ tự, được đánh giá dựa trên bảng đánh giá tình trang dinh dưỡng theo MNA, gồm có 3 giá trị dinh dưỡng bình thường (12 14 điểm), có nguy cơ suy dinh dưỡng (8 - 11 điểm), bị suy dinh dưỡng ( 0 - 7 điểm). Đái tháo đường được định nghĩa theo tiêu chuẩn của ADA 2019. Các biến số khác như tăng huyết áp, rối loạn lipid máu, hoạt động chức năng cơ bản hàng ngày $(A D L)$, hoạt động chức năng sinh hoạt hàng ngày (IADL) được định nghĩa theo các tiêu chuấn mới nhất hiện nay.

Xử lý thống kê: Các số liệu được nhập và xử lý bằng phần mềm SPSS 20.0. Biến định tính được trình bày dưới dang tỷ lê phần trăm, kiểm định sự khác biệt thống kê bằng phép kiểm chi 
bình phương. Biến định lượng được trình bày dưới dạng số trung bình ( \pm độ lệch chuẩn), kiểm định sự khác biệt của các tỷ lệ bằng test chi bình phương và so sánh giá trị trung bình giữa 2 nhóm theo t-test, mức khác biệt có ý nghĩa thống kê với $p<0,05$.

$Y$ đức nghiên cứu: Nghiên cứu này được thông qua Hội đồng đạo đức trong nghiên cứu $Y$ sinh học của Đại học Y dược Thành Phố Hồ Chí Minh theo quyết định số 637/ĐHYD-HĐĐĐ, tháng 11 năm 2019.

\section{KẾT QUẢ NGHIÊN CứU}

Trong thời gian nghiên cứu từ tháng 11/2019 đến tháng 03/2020, chúng tôi đã thu thập được

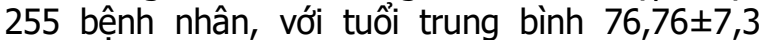
(tuổi), trong đó nam chiếm tỷ lệ $81,6 \%$. Đối tượng nghiên cứu chủ yếu là quân nhân chiếm hơn 2/3 dân số nghiên cứu, nhóm còn lại là người dân không phải quân nhân với tỷ lệ 26,3\%\%. Ngoài ra, các đặc điểm chung khác của dân số nghiên cứu được chúng tôi trình bày trong bảng 1.

Bảng 1. Đặc điểm chung của các đối tượng nghiên cứu

\begin{tabular}{|c|c|c|c|}
\hline & Đặc điếm & Tân số (n) & Tý lẹ (\%) \\
\hline & $60-69$ & 171 & 67,1 \\
\hline Tuổi & $70-79$ & 63 & 24,7 \\
\hline & $\geq 80$ & 21 & 8,2 \\
\hline & Tuối trung bình (TB \pm ĐLC) & 76,76 & $\pm 7,3$ \\
\hline Gión: & Nam & 208 & 81,6 \\
\hline - & Nữ & 47 & 18,4 \\
\hline Tình trạng & Còn vợ/ chông & 227 & 89 \\
\hline hôn nhâñ & Độc thân/ góa/ ly dị & 28 & 11 \\
\hline Tình trạng & Sống chung gia đình & 243 & 95,3 \\
\hline gia đình & Sống một mình & 12 & 4,7 \\
\hline & Thành phố Hồ Chí Minh & 255 & 100 \\
\hline Nol sinn song & Khác & 0 & 0 \\
\hline Đối tưona & Quân nhân & 188 & 73,7 \\
\hline vor tựig & Dân & 67 & 26,3 \\
\hline & Nhân viên văn phòng & 55 & 21,6 \\
\hline Nahồ nahiôn & Nông dân, công nhân, lái xe, tạp vụ, hộ lý & 14 & 5,5 \\
\hline Ngne ngniẹp & Tham mưu, sở chỉ huy, hậu cân, cục tài chính, tòa án & 155 & 60,7 \\
\hline & Nghề khác (bác sĩ, điều dưỡng, kỹ thuật, nhà báo...) & 31 & 12,2 \\
\hline Hút thuố & Có & 48 & 18,8 \\
\hline Hut tnuod & Không & 207 & 81,2 \\
\hline & Mù chữ & 2 & 0,8 \\
\hline & Cấp 1 & 4 & 1,6 \\
\hline Trình độ học & Cấp 2 & 28 & 11 \\
\hline vấn & Cấp 3 & 84 & 32,9 \\
\hline & Đại học & 106 & 41,6 \\
\hline & Sau đại học & 31 & 12,2 \\
\hline & Có & 199 & 78 \\
\hline Đa bẹnn & Không & 56 & 22 \\
\hline Đa thuốc & Có & 163 & 63,9 \\
\hline & Không & 92 & 36,1 \\
\hline
\end{tabular}

Bệnh nhân có thế trạng béo phì chiếm tỷ lệ rất cao 45,9\%, thế trạng gầy chiếm tỷ lệ thấp nhất $1,5 \%$, thể trạng trung bình $23,5 \%$. Suy giảm chức năng cơ bản hàng ngày (ADL) chiếm tỷ lệ rất thấp $0,8 \%(n=2)$, suy giảm IADL 5,4\% $(n=13)$. Số bệnh nhân có chế độ dinh dưỡng bình thường chiếm đa số $90,5 \%(n=231)$, có nguy cơ suy dinh dưởng hoặc bị suy suy dinh dưỡng chiếm tỷ lệ không đáng kể với lần lượt là $7,5 \%$ và $2 \%$ (bảng 2 ).

Bảng 2. Đặc điểm lầm sàng của dân sốnghiên cứu

\begin{tabular}{|c|c|c|c|}
\hline \multicolumn{2}{|c|}{ Đặc điếm } & Tân số (n) & Tỷ lệ (\%) \\
\hline \multirow{3}{*}{ Thể trạng } & Gầy & 4 & 1,5 \\
\cline { 2 - 4 } & Trung bình & 60 & 23,5 \\
\cline { 2 - 4 } & Thừa cân & 74 & 29 \\
\cline { 2 - 4 } & Béo phì & 117 & 45,9 \\
\hline
\end{tabular}


VIETNAM MEDICAL JOURNAL N01\&2 - FEBRUARY - 2021

\begin{tabular}{|c|c|c|c|}
\hline \multirow{2}{*}{ ADL } & 6 điếm & 253 & 99,2 \\
\cline { 2 - 4 } & $<6$ điếm & 2 & 0,8 \\
\hline \multirow{2}{*}{ IADL } & 8 điếm & 242 & 94,9 \\
\cline { 2 - 4 } & $<8$ điếm & 13 & 5,1 \\
\hline \multirow{2}{*}{$\begin{array}{c}\text { Tình trang dinh } \\
\text { dưỡng (MNA) }\end{array}$} & Tình trạng dinh dưỡng bình thường (12-14 điếm) & 231 & 90,5 \\
\cline { 2 - 4 } & Có nguy cơ suy dinh dưỡng (8 - 11 điếm) & 19 & 7,5 \\
\cline { 2 - 4 } & Bị suy dinh dưỡng (0 - 7 điếm) & 5 & 2 \\
\hline
\end{tabular}

Tỷ lề thiếu cơ chung trên các bênh nhân có đái tháo đường là 22,7\%. Khi phân tích trên các tiêu chí thành phần của thiếu cơ thì nhóm bệnh nhân có giai đoạn thiếu cơ nặng chiếm tỷ lệ thấp nhất $4,7 \%$, hai nhóm còn lại bao gồm tiền thiếu cơ và thiếu cơ có tỷ lệ lần lượt là $16,5 \%, 18 \%$.

Bảng 3. Mối liên quan giữa thiếu cơ và tất cả các đặc điểm

\begin{tabular}{|c|c|c|c|c|}
\hline \multicolumn{2}{|c|}{ Đặc điếm } & Thiếu cơ & Không thiếu cơ & $\mathbf{p}$ \\
\hline \multicolumn{2}{|c|}{ Tuối (TB \pm ĐLC) } & $73,45 \pm 8,75$ & $65,97 \pm 5,84$ & $<0,001$ \\
\hline \multirow{3}{*}{$\begin{array}{l}\text { Nhóm tuổi } \\
\mathrm{n}(\%)\end{array}$} & $60-69$ & $20(11,7)$ & $151(88,3)$ & \multirow{3}{*}{$<0,001$} \\
\hline & $70-79$ & $23(36,5)$ & $40(63,5)$ & \\
\hline & $\geq 80$ & $15(71,4)$ & $6(28,6)$ & \\
\hline \multirow{2}{*}{ Giới, n(\%) } & Nam & $49(23,6)$ & $159(76,4)$ & \multirow{2}{*}{0,52} \\
\hline & Nũ̃ & $9(19,1)$ & $38(80,9)$ & \\
\hline Dân tộc, n(\%) & Kinh & $58(22,7)$ & $197(77,3)$ & 1,00 \\
\hline Địa chí, n(\%) & TP Hồ Chí Minh & $58(22,7)$ & $197(77,3)$ & 1,00 \\
\hline \multirow{4}{*}{$\begin{array}{l}\text { Nghề nghiệp } \\
\text { n(\%) }\end{array}$} & Nhân viên văn phòng & $9(16,4)$ & $46(83,6)$ & \multirow{4}{*}{0,6} \\
\hline & $\begin{array}{c}\text { Nông dân, công nhân, lái xe, } \\
\text { tap vu, hô lý }\end{array}$ & $2(16,7)$ & $12(83,3)$ & \\
\hline & $\begin{array}{l}\text { Tham mưu, sở chỉ huy, hậu } \\
\text { cân, cục tài chính, tòa án }\end{array}$ & $38(24,5)$ & $117(75,5)$ & \\
\hline & Khác & $9(29)$ & $22(71)$ & \\
\hline \multirow{2}{*}{ Đối tượng, n(\%) } & Quân nhân & $44(23,4)$ & $144(76,6)$ & \multirow{2}{*}{0,67} \\
\hline & Dân & $14(20,9)$ & $53(79,1)$ & \\
\hline \multirow{6}{*}{ Hoc vấn, n(\%) } & Mù chữ & $0(0)$ & $2(100)$ & \multirow{6}{*}{0,25} \\
\hline & Cấp 1 & $1(25)$ & $3(75)$ & \\
\hline & Cấp 2 & $11(39,3)$ & $17(60,7)$ & \\
\hline & Cấp 3 & $19(22,6)$ & $65(77,4)$ & \\
\hline & Đại học & $19(17,9)$ & $87(82,1)$ & \\
\hline & Sau đai hoc & $8(25,8)$ & $23(74,2)$ & \\
\hline \multirow{2}{*}{ Hôn nhân, n(\%) } & Độc thân, góa, ly dị & $7(25)$ & $21(75)$ & \multirow{2}{*}{0,76} \\
\hline & Còn vớ/chồng & $51(22,5)$ & $176(77,5)$ & \\
\hline \multirow{2}{*}{ Gia đình, n(\%) } & Sống với gia đình & $55(22,6)$ & $188(77,4)$ & \multirow{2}{*}{0,74} \\
\hline & Sống một mình & $3(25)$ & $9(75)$ & \\
\hline \multirow{2}{*}{ Thuốc lá, n(\%) } & Có & $11(22,9)$ & $37(77,1)$ & \multirow{2}{*}{0,98} \\
\hline & Không & $47(22,7)$ & $160(77,3)$ & \\
\hline \multirow{3}{*}{ Chăm sóc, n(\%) } & Tự chăm sóc & $4(26,7)$ & $11(73,3)$ & \multirow{3}{*}{0,8} \\
\hline & Vợ/chồng & $48(22)$ & $170(78)$ & \\
\hline & Con & $6(27,3)$ & $16(72,7)$ & \\
\hline \multirow{2}{*}{ Vận động, n(\%) } & Có & $31(18,5)$ & $137(81,5)$ & \multirow{2}{*}{0,02} \\
\hline & Không & $27(31)$ & $60(69)$ & \\
\hline \multirow{2}{*}{ Té ngã, n(\%) } & Có & $11(30,6)$ & $25(69,4)$ & \multirow{2}{*}{0,23} \\
\hline & Không & $47(21,5)$ & $172(78,5)$ & \\
\hline \multirow{2}{*}{ Gãy xương, n(\%) } & Có & $2(18,2)$ & $9(81,8)$ & \multirow{2}{*}{0,71} \\
\hline & Không & $56(23)$ & $188(77)$ & \\
\hline Thời gian mắc bệnh đái & $<5$ năm & $8(10,4)$ & $69(89,6)$ & ב002 \\
\hline tháo đường, n(\%) & $\geq 5$ năm & $50(28,1)$ & $128(71,9)$ & 0,002 \\
\hline & Thuốc viên & $47(21,7)$ & $170(78,3)$ & \\
\hline đường n(\%) & Insulin & $10(50)$ & $10(50)$ & 0,004 \\
\hline & Thuốc viên và insulin & $1(5,6)$ & $17(94,4)$ & \\
\hline
\end{tabular}




\begin{tabular}{|c|c|c|c|c|}
\hline \multirow{3}{*}{ Dinh dương, n(\%) } & Binh thường & $47(20,3)$ & $184(79,7)$ & \multirow{3}{*}{0,006} \\
\hline & Nguy cơ suy dinh dưỡng & $10(52,6)$ & $9(47,4)$ & \\
\hline & Suy dinh dưỡng & $1(20)$ & $4(80)$ & \\
\hline \multirow{4}{*}{ Thể trạng, n(\%) } & Gầy & $3(75)$ & $1(25)$ & \multirow{4}{*}{$<0,001$} \\
\hline & Bình thường & $27(45)$ & $33(55)$ & \\
\hline & Thừa cân & $21(28,4)$ & $53(71,6)$ & \\
\hline & Béo phì & $7(6)$ & $110(94)$ & \\
\hline \multirow{2}{*}{ Tăng huyết áp, n(\%) } & Có & $27(19)$ & $115(81)$ & \multirow{2}{*}{0,11} \\
\hline & Không & $31(27,4)$ & $82(72,6)$ & \\
\hline \multirow{3}{*}{ Mức đường huyết, n(\%) } & Tốt & $33(24,8)$ & $100(75,2)$ & \multirow{3}{*}{0,35} \\
\hline & Chấp nhận được & $16(17,8)$ & $74(82,2)$ & \\
\hline & Kém & $9(28,1)$ & $23(71,9)$ & \\
\hline \multirow{2}{*}{ Rối loạn lipid máu, n(\%) } & Có & $37(23,7)$ & $119(76,3)$ & \multirow{2}{*}{0,64} \\
\hline & Không & $21(21,2)$ & $78(78,8)$ & \\
\hline \multirow{3}{*}{ Mức HbA1C, n(\%) } & Tốt & $36(21,8)$ & $129(78,2)$ & \multirow{3}{*}{0,74} \\
\hline & Chấp nhận được & $12(22,2)$ & $42(77,8)$ & \\
\hline & Kém & $10(27,8)$ & $26(72,2)$ & \\
\hline \multirow{2}{*}{ Đa bệnh, n(\%) } & Có & $43(21,6)$ & $156(78,4)$ & \multirow{2}{*}{0,41} \\
\hline & Không & $15(26,8)$ & $41(73,2)$ & \\
\hline \multirow[t]{2}{*}{ Đa thuốc, n(\%) } & Có & $41(25,2)$ & $122(74,8)$ & \multirow{2}{*}{0,22} \\
\hline & Không & $17(18,5)$ & $75(81,5)$ & \\
\hline \multirow{2}{*}{ Giảm ADL, n(\%) } & Có & $0(0)$ & $2(100)$ & \multirow{2}{*}{1,00} \\
\hline & Không & $58(22,9)$ & $195(77,1)$ & \\
\hline \multirow{2}{*}{ Giảm IADL, n(\%) } & Có & $11(68,8)$ & $5(31,2)$ & \multirow{2}{*}{$<0,001$} \\
\hline & Không & $47(19,7)$ & $192(80,3)$ & \\
\hline
\end{tabular}

Chú thích: TB: trung bình, ĐLC: độ lêch chuẩn

Khảo sát về mối liên quan giữa thiếu cơ với một số yếu tố khác, chúng tôi đã ghi nhận và trình bày trong bảng 3 . Khi phân tích logistic đa biến, chúng tôi ghi nhận chỉ có 2 yếu tố là thời gian mắc bệnh đái tháo đường ( $\mathrm{OR}=0,37, \mathrm{KTC}$ $95 \% 0,14-0,98, p=0,045)$ và thể trạng $(\mathrm{OR}=$ $4,57, \mathrm{KTC} 95 \% 2,76-7,56, \mathrm{p}<0,001)$ là có liên quan với thiếu cơ (bảng 4).

Bảng 4. Mối liên quan thiêu cơ và tất cả các đặc điểm qua phân tích hồi quy logistic đa biến

\begin{tabular}{|c|c|c|c|}
\hline Đặc điếm & OR & KTC 95\% & $\mathbf{p}$ \\
\hline Tuối & 0,88 & $0,78-1,00$ & 0,68 \\
\hline Nhóm tuối & 0,72 & $0,17-2,99$ & 0,65 \\
\hline Vận động & 0,64 & $0,27-1,5$ & 0,3 \\
\hline $\begin{array}{c}\text { Thời gian mắc bệnh } \\
\text { đái tháo đường }\end{array}$ & 0,37 & $0,14-0,98$ & 0,045 \\
\hline $\begin{array}{c}\text { Thuốc điều trị đái } \\
\text { tháo đường }\end{array}$ & 1,00 & $0,48-2,08$ & 0,99 \\
\hline Dinh dưỡng & 1,63 & $0,61-4,37$ & 0,33 \\
\hline Thể trạng & 4,57 & $2,76-7,56$ & $<0,001$ \\
\hline Giảm IADL & 1,93 & $0,39-9,56$ & 0,42 \\
\hline
\end{tabular}

\section{BÀN LUẬN}

Tuổi trung bình trong dân số nghiên cứu của chúng tôi là 76,76 $\pm 7,3$ tuổi. Kết quả này tương tự với nghiên cứu của tác giả Maria Rosaria Rizzo và cộng sự [4] ở 80 bệnh nhân cao tuổi mắc bệnh ĐTÐ tại Italy với tuổi trung bình của dân số nghiên cứu là 76,2 $\pm 5,4$ tuổi. Ngoài ra, một số nghiên cứu khác về ĐTĐ trên NCT cũng ghi nhân kết quả tương tự, như kết quả nghiên cứu của tác giả Ken Sugimoto [5] và Tanaka [6]. Ngược lại, một vài nghiên cứu khác lại cho kết quả tuổi trung bình thấp hơn chúng tôi. Cụ thể, theo nghiên cứu của tác giả Foon Yin Fung [7] ghi nhận tuổi trung bình của dân số nghiên cứu là $68,3 \pm 5,66$ tuổi, sự khác biệt có thể do địa điểm nghiên cứu khác nhau.

Tỷ lệ thiếu cơ chung trong nghiên cứu của chúng tôi là $22,7 \%$. Kết quả này tương tự với nghiên cứu của tác giả Tanaka [6] có tỷ lệ thiếu cơ là 25,5\%. Sự khác biệt có thể do đối tượng nghiên cứu của tác giả Gariballa là tất cả các bệnh nhân trong khoa cấp cứu có hay không có bệnh nền đều đưa vào nghiên cứu, trong khi chúng tôi chỉ chọn các bệnh nhân bị ĐTĐ típ 2 . Đồng thời, khi so sánh với kết quả nghiên cứu của tác giả tác giả Lara Bianchi [8] thì kết quả của chúng tôi thấp hơn. Theo nghiên cứu của tác giả Lara Bianchi [8] tại khoa Lão và khoa Cấp Cứu ở Italy ghi nhận tỳ lệ thiếu cơ trong dân số nghiên cứu là $34,75 \%$. Sự khác biệt này có thể do đối tượng nghiên cứu của chúng tôi và các tác giả không giống nhau, chúng tôi là các bệnh nhân ổn định ngoại trú, các tác giả trên là các bệnh nhân đang có tình trạng bệnh cấp tính phải nhập viện điều trị nội trú.

Khi phân tích mối liên quan giữa thiếu cơ và các đặc điểm nghiên cứu, chúng tôi nhận thấy 
tuổi càng cao thì nguy cơ, số lượng bênh nhân thiếu cơ càng tăng. Tuy nhiên, khi phân tích logistic đa biến thì tuổi không liên quan với thiếu cơ. Kết quả này khác với các nghiên cứu trước đó có thể do cõ̃ mẫu của chúng tôi chưa đủ lớn. Vân động là yếu tố có liên quan với thiếu cơ qua phép kiểm chi bình phương $(p<0,05)$, tương tự với kết quả nghiên cứu của tác giả Ken Sugimoto ${ }^{(5)}$. Mặt khác, trong nghiên cứu của tác giả Ken Sugimoto [5] khi phân tích về các thuốc điều trị ĐTĐ của nhóm dân số nghiên cứu, kết quả cho thấy dùng insulin là yếu tố có liên quan với thiếu cơ. Khi phân tích logistic đa biến, chúng tôi ghi nhận thời gian mắc bệnh ĐTÐ và thể trạng là hai yếu tố có liên quan với thiếu cơ. Kết quả này cũng tương tự với các nghiên cứu của các tác giả Ken Sugimoto, Foon Yin Fung đều kết luận thể trạng là yếu tố có liên quan với thiếu cơ $[5,7]$.

Hạn chế của nghiên cứu: đây là nghiên cứu quan sát, cỡ mẫu còn nhỏ và phần lớn bệnh nhân trong nghiên cứu là nam giới nên phần nào chưa phản ánh hết được tính đại diện cho dân số chung. Qua kết quả nghiên cứu này, có thể gợi ý cần các nghiên cứu toàn diện hơn trong tương lai.

\section{KẾT LUẬN}

Thiếu cơ chiếm tỷ lệ khoảng gần $1 / 4$ dân số người cao tuổi bị đái tháo đường típ 2. Thời gian bị đái tháo đường và thể trạng là hai yếu tố có liên quan đến thiếu cơ. Kết quả này gợi ý cần phải tầm soát thiếu cơ trên bệnh nhân cao tuổi bị đái tháo đường típ 2 để có hướng can thiệp phù hợp.

\section{TÀI LIỆU THAM KHẢO}

1. Cruz-Jentoft AJ, Baeyens JP, Bauer J M, et al (2010). Sarcopenia: European consensus on definition and diagnosis: Report of the European Working Group on Sarcopenia in Older People. Age Ageing, 39 (4): 412-23.

2. Wang $T$, Feng $X$, Zhou J, et al (2016). Type 2 diabetes mellitus is associated with increased risks of sarcopenia and pre-sarcopenia in Chinese elderly. Scientific reports, 6 .

3. Chen L. K, Liu I. K, Woo J, et al (2014). Sarcopenia in Asia: consensus report of the Asian Working Group for Sarcopenia. J Am Med Dir Assoc, 15 (2): 95-101.

4. Maria RR, Michelangela $B$, Ilaria $F$, at el (2016). Sarcopenia in Elderly Diabetic Patients: Role of Dipeptidyl Peptidase 4 Inhibitors. JAMDA 17: 896-901.

5. Ken S, Yasuharu T, Hiroshi $I$, at al (2019). Hyperglycemia in non-obese patients with type 2 diabetes is associated with low muscle mass: The Multicenter Study for Clarifying Evidence for Sarcopenia in Patients with Diabetes Mellitus. J Diabetes Investig, 10: 1471-1479.

6. Tanaka $S$, Kamiya $K$, Hamazaki $N$, et a (2017). Utility of SARC-F for Assessing Physical Function in Elderly Patients With Cardiovascular Disease. J Am Med Dir Assoc, 18 (2): 176-181.

7. Foon YF, Yi Ling EK, Rahul M (2019). Prevalence of and factors associated with sarcopenia among multi-ethnic ambulatory older Asians with type 2 diabetes mellitus in a primary care setting. BMC Geriatrics, 19: 122.

8. Lara Bianchi, Stefano Volpato (2016). Muscle dysfunction in type 2 diabetes: a major threat to patient's mobility and independence. Acta Diabetologic, 53: 879-889.

\section{ĐÁNH GIÁ HIỆU QUẢ ĐIỀU TRI CỦA VIÊN NANG TAVINGA TRÊN BÊ̂NH NHÂN PHÌ ĐẠI LÀNH TÍNH TUYẾN TIỀN LIỆT}

\begin{tabular}{|c|c|}
\hline \multicolumn{2}{|c|}{$\begin{array}{l}\text { Phạm Khắc Linh }{ }^{1} \text {, Đào Nguyên Mạnh }{ }^{1} \text {, Trần Thanh Tuấn }{ }^{1} \text {, } \\
\text { Quách Thị Quỳnh }{ }^{1},{\text { Nguyễn Việt } \text { Nam }^{2} \text {, Phạm Ngọc Quang1, Lê Văn Quang }}^{1}\end{array}$} \\
\hline 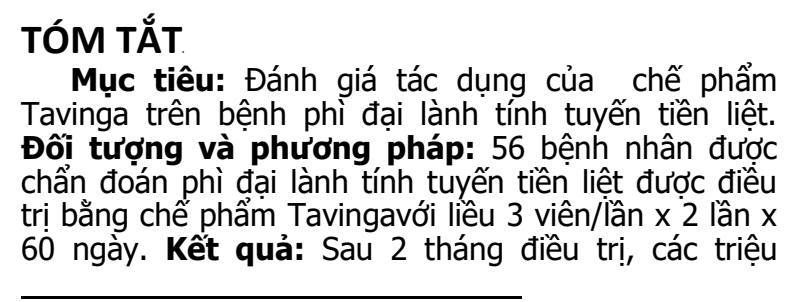 & 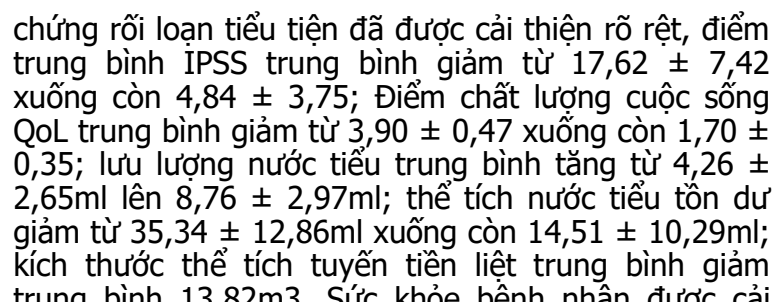 \\
\hline 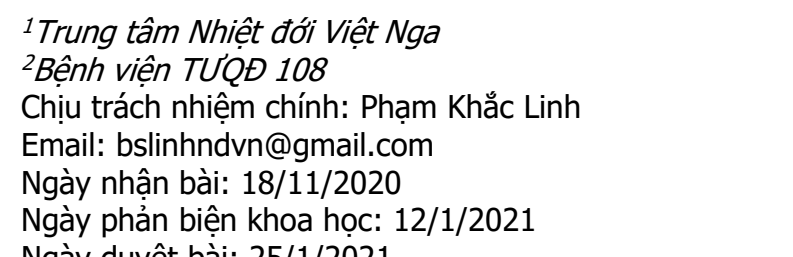 & 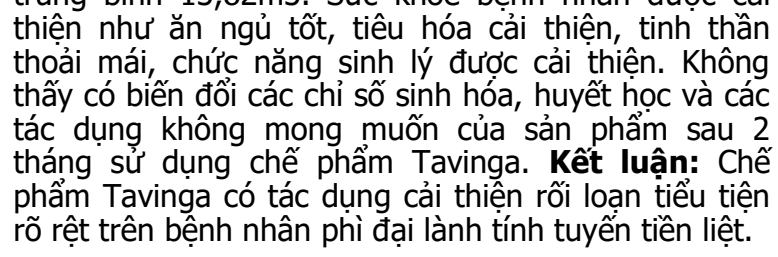 \\
\hline
\end{tabular}

